\title{
Heterogeneous Fenton process using steel industry wastes for methyl orange degradation
}

\author{
Mohamed E. M. Ali • Tarek A. Gad-Allah • \\ Mohamed I. Badawy
}

Received: 25 August 2012 / Accepted: 2 January 2013/Published online: 20 January 2013

(C) The Author(s) 2013. This article is published with open access at Springerlink.com

\begin{abstract}
Steel industry wastes (iron-containing waste) could be used as a Fenton-catalyst for the decolorization of methyl orange dye. Various reaction conditions were investigated including catalyst concentration, hydrogen peroxide concentration and $\mathrm{pH}$ value. The obtained results indicated that the dye degradation rate increases with increasing catalyst and hydrogen peroxide $\left(\mathrm{H}_{2} \mathrm{O}_{2}\right)$ concentrations and with decreasing $\mathrm{pH}$ value. Over $98 \%$ decolorization of the dye was achieved within $30 \mathrm{~min}$ at optimum reaction conditions; $200 \mathrm{mg} / \mathrm{L}$ catalyst and $34 \mathrm{mM} \mathrm{H} \mathrm{H}_{2} \mathrm{O}_{2}$ concentrations at $\mathrm{pH} 2$ for $20 \mathrm{mg} / \mathrm{L}$ initial dye concentration. Reaction kinetics was also carried out to determine the order of reaction in both catalyst and $\mathrm{H}_{2} \mathrm{O}_{2}$ concentrations. Stability and reusability of Iron-containing waste were investigated. The iron-containing waste as catalyst can be reused several times with nearly same efficiency of Fenton-like oxidation of MO.
\end{abstract}

Keywords Steel waste $\cdot$ Fenton-like reaction $\cdot$ Methyl orange $\cdot$ Decolorization

\section{Introduction}

Textile dyeing process produced large amounts of wastewater that are discharged into the environment. These effluents usually contain several classes of toxic dyes that exhibit low biodegradability and/or increased toxicity. Thus, effluents not only deteriorate the receiving waters,

M. E. M. Ali $(\bowtie)$ · T. A. Gad-Allah · M. I. Badawy

Water Pollution Research Department, National Research

Centre, Cairo 12311, Egypt

e-mail: alienv81@yahoo.com but also pose significant threat to the aquatic life because of the oxygen deficiency and formation of some toxic products by hydrolysis of dyes in the wastewater. Most of textile dyes are designed to produce long-lasting colors and are resistant to mild oxidation conditions. Therefore, stronger oxidation process is needed to degrade these structures (Dukkanc et al. 2010). For that purpose, advanced oxidation technologies (AOTs) were extensively investigated. These processes rely on the generation of extremely active $\mathrm{OH}$ radicals, which are identified as strong and non-selective oxidants of almost all organic compounds ( $\mathrm{Li}$ et al. 2006). As one of AOTs, Fenton-like (Heterogeneous Fenton) process was used to generate the powerful hydroxyl radicals from $\mathrm{H}_{2} \mathrm{O}_{2}$ in the presence of iron as $\mathrm{Fe}^{2+}$ or $\mathrm{Fe}^{3+}$, to decompose many organic compounds including dyes (Dukkanc et al. 2010).

In case of Heterogeneous Fenton reaction, soluble $\mathrm{Fe}^{2+}$ catalyst is replaced by $\mathrm{Fe}$-containing solids. This kind of Fenton reaction has been proved to be also effective in the treatment of industrial wastewater containing non-biodegradable organic pollutants. Furthermore, this process has numerous advantages over classical homogenous Fenton catalysis; e.g. no iron sludge is generated and easy separation of the catalyst from the treated stream (Bautista et al. 2008; Garrido-Ramirez et al. 2010). Various heterogeneous Fenton-like catalysts such as $\mathrm{Fe}_{2} \mathrm{O}_{3}$ (Feng et al. 2004), S-doped $\mathrm{Fe}_{2} \mathrm{O}_{3}$ (Guo et al. 2010) and $\mathrm{Fe}_{3} \mathrm{O}_{4}$ (Zhang et al. 2008) were used for wastewater treatment. Unfortunately, a lot of these catalysts do not exhibit favorable catalytic activity at neutral $\mathrm{pH}$ and the working $\mathrm{pH}$ values are usually around 3 . Therefore, acidifying the wastewater or inputting external energy into the reaction system is a frequently used method to enhance their activity (Muthukumari et al. 2009; Cruz-González et al. 2010; Li et al. 2010). So it is worth to use low cost catalyst to reduce the overall cost 
of the treatment process while keeping reasonable efficiency.

In this study, the waste produced from steel industry was used as a catalyst in heterogeneous Fenton oxidation process. Steel is manufactured by the chemical reduction of iron ore, using an integrated steel manufacturing process or a direct reduction process. In the conventional integrated steel manufacturing process, the iron from the blast furnace is converted to steel in a basic oxygen furnace (BOF). Steel can also be made in an electric arc furnace (EAF) from scrap steel and, in some cases, from direct reduced iron. Three major waste streams are generated during steel manufacturing, air emissions, wastewater and solid waste. The solid waste from the conventional process, including furnace slag and collected dust, is generated at an average rate ranging from $300 \mathrm{~kg} / \mathrm{t}$ of steel manufactured to $500 \mathrm{~kg} / \mathrm{t}$. This waste is rich in iron and can be used as a catalyst in heterogeneous Fenton process for wastewater treatment. The use of iron-containing waste in the treatment of wastewater will hopefully reduce the cost of wastewater treatment.

This work focuses on the use of iron-containing waste instead of iron salts as a catalyst in heterogeneous Fenton process using methyl orange as a model compound for dye wastewater. The effect of different reaction conditions (e.g. $\mathrm{pH}$ value, catalyst dose, hydrogen peroxide concentration and initial dye concentration) on degradation of dye was assessed along with catalyst reusability.

\section{Experimental}

\section{Reagents}

All chemicals used in this study were of analytical grade and were used without further purification. Iron-containing waste was kindly supplied by Egyptian Company for Iron and Steel and was used after sieving to fine powder. $\mathrm{H}_{2} \mathrm{O}_{2}$ (30 \%, v/v) and methyl orange $\left(\mathrm{C}_{14} \mathrm{H}_{14} \mathrm{~N}_{3} \mathrm{NaO}_{3} \mathrm{~S}\right.$; Fig. 1) were purchased from Fluka Company (Germany). Double distilled water was used for the preparation of dye solutions.

Analysis and procedure

XRD pattern of iron-containing waste (catalyst) was recorded on Bruker diffractometer equipped with graphite monochromatized $\mathrm{Cu}-\mathrm{K}_{\alpha}$ radiation (Germany). Amount of

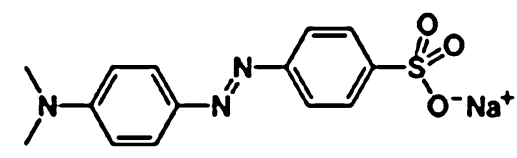

Fig. 1 Chemical structure of methyl orange dye leached iron was determined with the aid of atomic absorption spectrometer (Varian, Spectra AA 220). All experiments were conducted in conical flask $(250 \mathrm{~mL})$ placed on orbital shaker (Stuart scientific, UK) with $200 \mathrm{rpm}$ rotation speed and under dark circumstance. The reaction suspension containing specified concentrations of both MO dye and steel waste was prepared, and its initial $\mathrm{pH}$ was adjusted by diluted $\mathrm{H}_{2} \mathrm{SO}_{4}$. The experiments were initiated by adding the desired amount of $\mathrm{H}_{2} \mathrm{O}_{2}$ to the reaction mixture. Five milliliter samples were collected at pre-determined time intervals during the reaction, and then $\mathrm{NaOH}$ was immediately added to the sample as reaction inhibitor because at first, $\mathrm{H}_{2} \mathrm{O}_{2}$ is not stable in alkaline solution and second, the formation of ferric hydroxide complexes leads to a reduction of $\cdot \mathrm{OH}$ radical $(\mathrm{Ji}$ et al. 2011). Samples were allowed to settle for short time before measuring absorbance at $\lambda_{\max }$ of methyl orange by UVVisible spectrophotometer (Jasco V530, Japan).

\section{Results and discussion}

XRD characterization of steel industry waste

Iron-containing waste used in this study contains about $90 \%$ of iron as detected by atomic absorption spectrometer. Figure 2 shows XRD pattern of steel industry waste. The diffraction peaks match well with magnetite $\left(\mathrm{Fe}_{3} \mathrm{O}_{4}\right)$ (PDF\#72-2303), hematite $\left(\mathrm{Fe}_{2} \mathrm{O}_{3}\right)$ (PDF\#871165) and wuestite $\left(\mathrm{Fe}_{0.925} \mathrm{O}\right)$ (PDF\#89-0689). The major phase was magnetite $\left(\mathrm{Fe}_{3} \mathrm{O}_{4}\right)$ which provides magnetic property to this waste leading to easy electromagnetic separation from the treated wastewater.

Heterogeneous Fenton catalytic activity of steel industry waste

To assess the catalytic activity of iron-containing waste as a catalyst for the degradation of MO via heterogeneous Fenton process, experiments were conducted under different reaction conditions; (1) $\mathrm{H}_{2} \mathrm{O}_{2}$ only, (2) catalyst only, and (3) catalyst and $\mathrm{H}_{2} \mathrm{O}_{2}$. Figure 3 shows the decolorization rate of $40 \mathrm{mg} / \mathrm{L}$ of $\mathrm{MO}$ as a function of time at the pre-mentioned conditions. Low and negligible decolorization rate was observed under condition (1) due to the limited oxidation ability of $\mathrm{H}_{2} \mathrm{O}_{2}$ compared to hydroxyl radical. While, using steel industry waste led to decolorization efficiency of $21 \%$ after $2 \mathrm{~h}$ because of adsorption capability of the catalyst. However, with simultaneous presence of catalyst and $\mathrm{H}_{2} \mathrm{O}_{2}$, decolorization efficiency was very close to $98 \%$ within $2 \mathrm{~h}$ revealing that ironcontaining waste exhibited an excellent catalytic activity and could react with $\mathrm{H}_{2} \mathrm{O}_{2}$ to generate more radicals. 
Fig. 2 XRD pattern of steel industry waste; (filled triangle) magnetite, (closed circle) hematite and (open circle) Wüstite phases

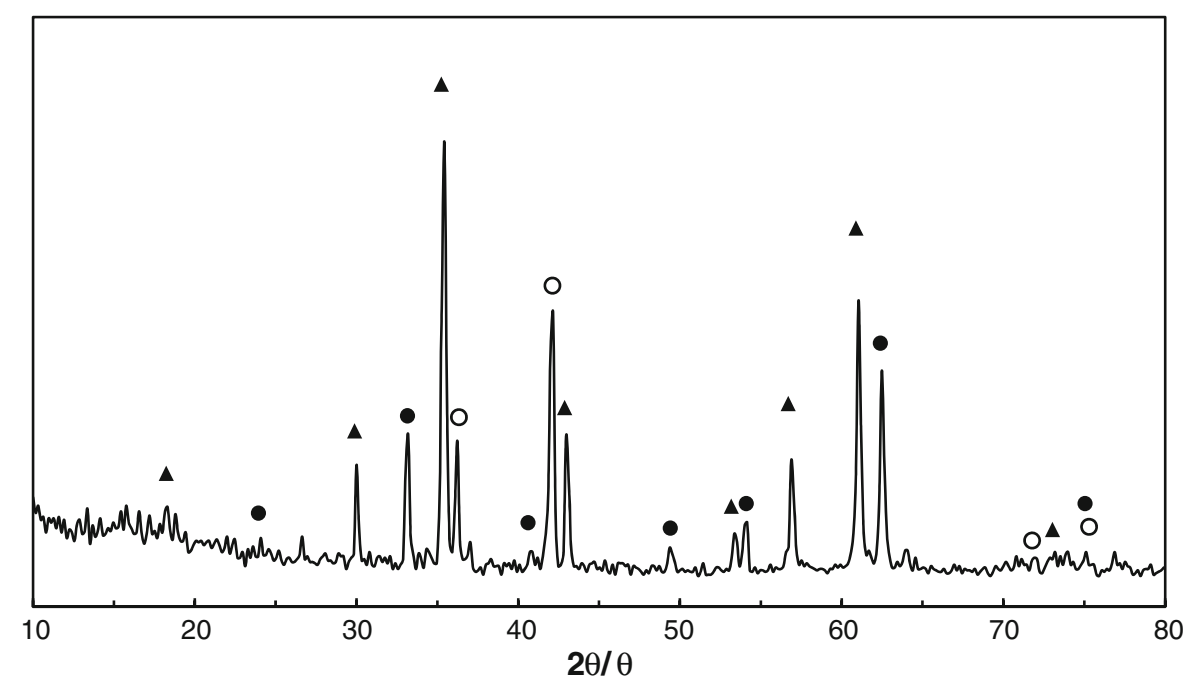

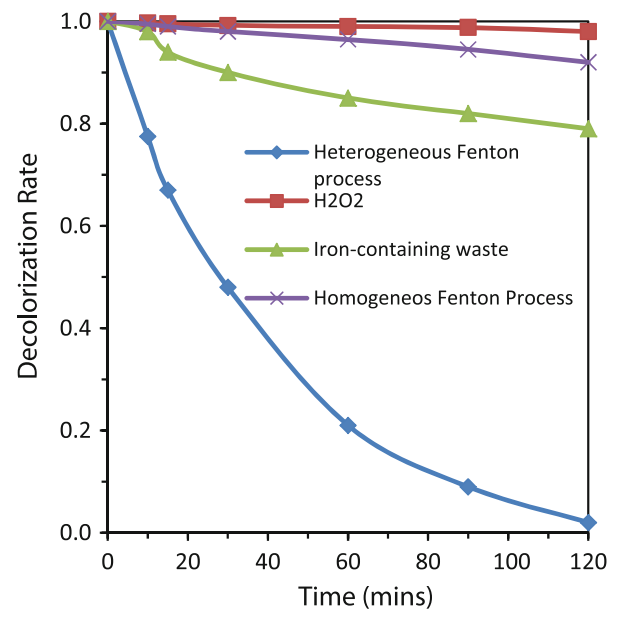

Fig. 3 Efficiency of MO decolorization using (1) $\mathrm{H}_{2} \mathrm{O}_{2}$, (2) $200 \mathrm{mg} / \mathrm{L}$ Iron-containing waste, (3) $200 \mathrm{mg} / \mathrm{L}$ catalyst and $\mathrm{H}_{2} \mathrm{O}_{2}$ (heterogeneous Fenton process), and (4) $1.9 \mathrm{mg} / \mathrm{L} \mathrm{Fe}^{3+}$ and $\mathrm{H}_{2} \mathrm{O}_{2}$ (Homogeneous Fenton process). Reaction conditions: $40 \mathrm{mg} / \mathrm{L} \mathrm{MO}, 30 \mathrm{mM} \mathrm{H}_{2} \mathrm{O}_{2}$, and $\mathrm{pH} 4$

To exclude the possibility of homogeneous Fenton reaction by the leached iron, the concentration of leached iron was measured using atomic absorption spectrometer and was found to be $0.15 \mathrm{mg} / \mathrm{L}$. Then, homogeneous Fenton process was carried out using the same concentration of iron that was leached out from the catalyst. Under the same operating conditions, the decolorization efficiency of homogeneous Fenton process after $2 \mathrm{~h}$ was only $8 \%$ which was much less than that in case of heterogeneous system using iron-containing waste. Therefore, the catalytic activity has been primarily attributed to the steel industry waste catalyst and not to the dissolved iron ions.

A plausible mechanism of Fenton-like reaction using iron-containing waste as a catalyst is illustrated in Eqs. 1-3. Steel industry waste contains Wüstite $\left(\mathrm{Fe}_{0.925} \mathrm{O}\right)$ which could participate in Fenton reaction according to Eq. 1.
The co-presence of both $\mathrm{Fe}_{3} \mathrm{O}_{4}$ and $\mathrm{Fe}_{2} \mathrm{O}_{3}$ oxides (Fig. 2) may enhance Fenton process by catalyst regeneration through a series of reactions involving hydroperoxyl radicals $\left(\mathrm{HO}_{2} \cdot\right)$ intermediate (Eqs. 2, 3) and hence, more hydroxyl radicals are generated in the system.

$$
\begin{aligned}
& \mathrm{Fe}^{2+}+\mathrm{H}_{2} \mathrm{O}_{2} \rightarrow \mathrm{Fe}^{3+}+\cdot \mathrm{OH}+\mathrm{OH}^{-} \\
& \mathrm{Fe}^{3+}+\mathrm{H}_{2} \mathrm{O}_{2} \rightarrow \mathrm{Fe}^{2+}+\mathrm{HO}_{2}+\mathrm{H}^{+} \\
& \mathrm{Fe}^{3+}+\mathrm{HO}_{2} \rightarrow \mathrm{Fe}^{2+}+\mathrm{O}_{2}+\mathrm{H}^{+}
\end{aligned}
$$

\section{Effect of $\mathrm{pH}$}

$\mathrm{pH}$ of wastewater has an important effect on heterogeneous Fenton process because $\mathrm{pH}$ controls the catalytic activity in the course of affecting the oxidant, the substrate, the dominant iron species, and the stability of hydrogen peroxide (Xu and Wang 2011). Thus, the effect of $\mathrm{pH}$ on the MO decolorization by iron-containing waste was investigated at $\mathrm{pH}$ range from 2 to 5 (Fig. 4). The results showed that the decolorization rate decreased with the reduction in $\mathrm{pH}$ value which is in agreement with classical Fenton process. The complete decolorization of MO was achieved within $60 \mathrm{~min}$ at $\mathrm{pH} 2$. While at $\mathrm{pH} 5$, only $55 \%$ decolorization efficiency was gained at same reaction time. These results are also consistent with the previously reported data for the oxidative decolorization of Acid Red 1 solutions by $\mathrm{Fe}$-zeolite $\mathrm{Y}$ type catalyst (Hassan and Hameed 2011).

\section{Effect of initial dye concentration}

To study the effect of initial dye concentration on the decolorization efficiency, the experiments were carried out using different initial concentration of MO ranging from 10 to $80 \mathrm{mg} / \mathrm{L}$ while keeping other conditions invariable. The results are depicted in Fig. 5. The higher the initial dye 


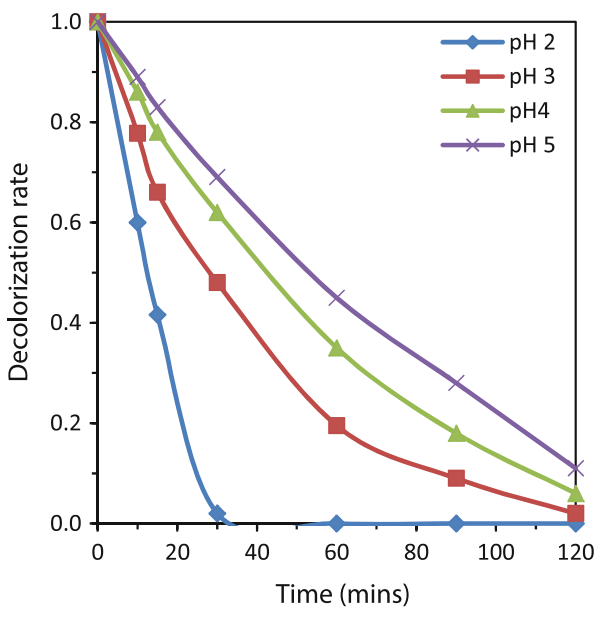

Fig. 4 Effect of $\mathrm{pH}$ on decolorization rate of $\mathrm{MO}$; Reaction conditions: $200 \mathrm{mg} / \mathrm{L}$ catalyst, $24 \mathrm{mM}$ of $\mathrm{H}_{2} \mathrm{O}_{2}$ and $40 \mathrm{mg} / \mathrm{L} \mathrm{MO}$

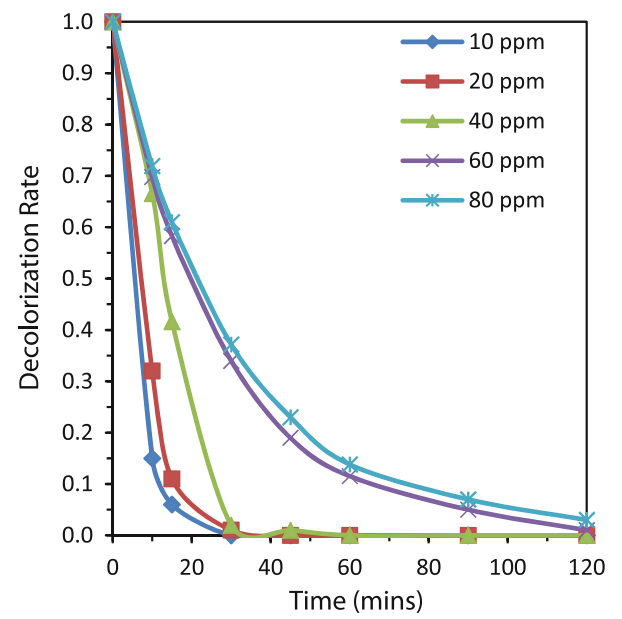

Fig. 5 Effect of initial dye concentration on decolorization of MO dye; Reaction conditions: $200 \mathrm{mg} / \mathrm{L}$ catalyst, $40 \mathrm{mM} \mathrm{H}_{2} \mathrm{O}_{2}$ and at $\mathrm{pH} 2$

concentration, the longer the time needed for MO degradation. For instance, the MO concentration was below the detectable level after $30 \mathrm{~min}$ for 10,20 and $40 \mathrm{mg} / \mathrm{L}$ initial dye concentrations, whereas 60 and $80 \mathrm{mg} / \mathrm{L}$ initial dye concentrations needed 120 min for 99 and $97 \%$ degradation efficiencies, respectively. This phenomenon might be due to the fact that the number of dye molecules is increased but number of $\mathrm{OH}$. is still constant. On the other hand, with the increase in initial concentration of the dye, more dye molecules were adsorbed onto the surface of catalyst (Zhang et al. 2009). Thereby, the generation of . OH radicals on the surface catalyst is reduced since the active sites were occupied by dye ions.

\section{Effect of catalyst and hydrogen peroxide concentrations}

Both the iron-containing waste and hydrogen peroxide concentrations have a significant effect on the rate of heterogeneous Fenton process as production of hydroxyl radicals depends mainly on these two factors according to Eq. 1. The influence of hydrogen peroxide concentration on decolorization rate of MO dye at different catalyst doses by heterogeneous Fenton process is illustrated in Fig. 6. In general, efficiency of heterogeneous Fenton degradation of MO dye increased, when both catalyst and hydrogen peroxide doses increased to some extent due to production of additional hydroxyl radicals.

The decolorization efficiency of MO increased when hydrogen peroxide concentration increased from 12 to $48 \mathrm{mM}$. However, further addition of $\mathrm{H}_{2} \mathrm{O}_{2}$ to the reaction retarded the color removal. This could be due to that hydrogen peroxide not being selectively converted to hydroxyl radicals but instead autodecomposed to water and oxygen and/or, once radicals have been generated, they are exhausted through scavenging reaction mechanisms by hydrogen peroxide itself to form hydroperoxyl radicals (Eq. 6) with a lower oxidizing power (Hassan and Hameed 2011); the latter can also scavenge hydroxyl radicals according to Eq. 7, (Liao et al. 2009).

$\mathrm{H}_{2} \mathrm{O}_{2}+\cdot \mathrm{OH} \rightarrow \mathrm{H}_{2} \mathrm{O}+\mathrm{HOO}$.

$\mathrm{HOO} \cdot+\cdot \mathrm{OH} \rightarrow \mathrm{H}_{2} \mathrm{O}+\mathrm{O}_{2}$

Decolorization rate was also found to increase with the increase in catalyst (iron-containing waste) concentration till reaching maximum value and then slightly decreased upon further addition of the catalyst (Fig. 6). Same phenomenon has been reported by Liao et al. (2009). The inhibition effect of iron species is considered as the reason for this decrease because the scavenging of hydroxyl radicals or other radicals occurs when presenting excessive metal species, which can be expressed by the following equations (Lam et al. 2005; Ramirez et al. 2007; Romero et al. 2009).

$\mathrm{Fe}^{2+}+\cdot \mathrm{OH} \rightarrow \mathrm{Fe}^{3+}+\mathrm{OH}^{-}$

$\mathrm{Fe}^{2+}+\cdot \mathrm{OOH} \rightarrow \mathrm{Fe}^{3+}+\mathrm{OOH}^{-}$

Thus, it could be concluded that the optimum catalyst and hydrogen peroxide concentrations for degradation $\mathrm{MO}$ dye are $200 \mathrm{mg} / \mathrm{L}$ and $24 \mathrm{mM}$, respectively.

Kinetics of dye decolorization by heterogeneous Fenton reaction

From engineering point of view, it is useful to find out rate equation that fits the experimental data. So, the kinetics of heterogeneous Fenton reaction was studied extensively. The change in the MO concentration with time was described by zero-, half-, and first- and second-order kinetics (Fig. 7) according to Eqs. 10, 11, 12 and 13, respectively, where $C_{\mathrm{MO}_{t}}$ is the $\mathrm{MO}$ concentration at time $t$, 
Fig. 6 Effect of hydrogen peroxide and Catalyst concentrations on degradation rate of MO; a 50, b 100, c 200 and d $250 \mathrm{mg} / \mathrm{L}$ catalyst concentrations; Reaction conditions: $\mathrm{pH} 2$ and $20 \mathrm{mg} / \mathrm{L}$ MO
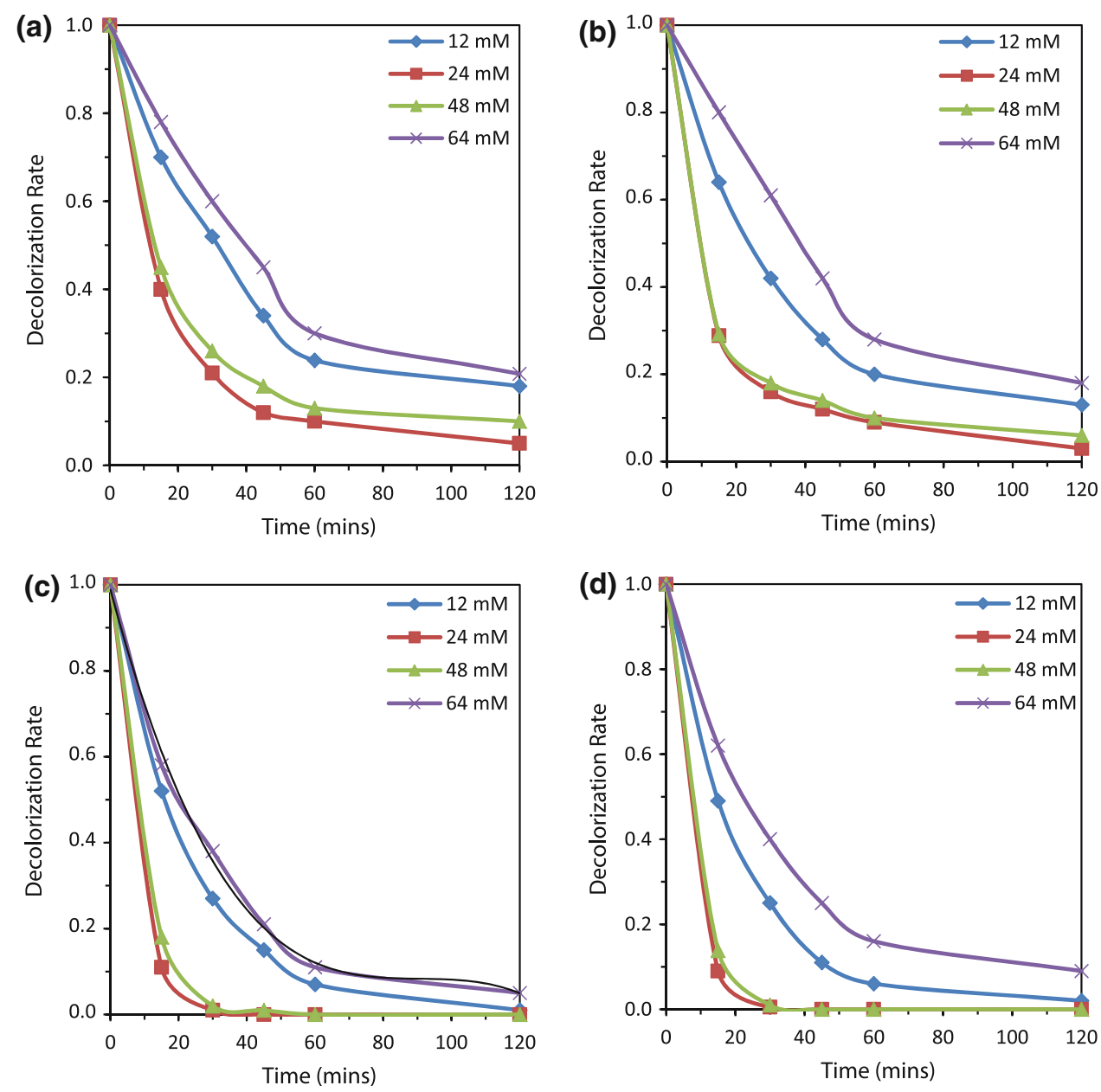

$C_{\mathrm{MO}_{0}}$ is the initial $\mathrm{MO}$ concentration and $t$ is time; $k_{0}, k_{0.5}$, $k_{1}$, and $k_{2}$ are the rate constants of the zero-, half-, first- and second-order kinetics, respectively.

$$
\begin{aligned}
& C_{t}=C_{0}-k_{0} t, \quad t_{1 / 2}=\frac{C_{0}}{2 k_{0}} \\
& \sqrt{C_{t}}=\sqrt{C_{0}}-\frac{k_{0.5}}{2} t, \quad t_{1 / 2}=\frac{0.59 \sqrt{C_{0}}}{k_{0.5}} \\
& \ln C_{t}=\ln C_{0}-k_{1} t, \quad t_{1 / 2}=\frac{\ln 2}{k_{1}} \\
& \frac{1}{C_{t}}=\frac{1}{C_{0}}+k_{2} t, \quad t_{1 / 2}=\frac{1}{C_{0} k_{2}}
\end{aligned}
$$

Table 1 represents the calculated reaction rate constants, half-life time and linear correlation coefficient $\left(R^{2}\right)$. At all concentrations of MO, the heterogeneous Fenton degradation of MO is more pronounced in the case of first-order kinetics compared with other orders because reaction rate constant decreases with the increase in initial dye concentration which is consistent with observed data. Also, comparing $t_{1 / 2}$ values deduced from Fig. 5 and from Eqs. 10 and 11 confirms that removal of $\mathrm{MO}$ via heterogeneous Fenton reaction can be described well by first-order kinetics.

It was previously shown that the rate of heterogeneous Fenton oxidation of MO depends mainly on catalyst dose and hydrogen peroxide concentration. Hence, the rate of MO degradation equation can be expressed as in Eq. 15 .

$-\frac{\mathrm{d} C_{\text {Dye }}}{\mathrm{d} t}=k C_{\text {Dye }}^{1} C_{\mathrm{Fe}}^{m} C_{\mathrm{H}_{2} \mathrm{O}_{2}}^{n}$

where $C_{\mathrm{dye}}, C_{\mathrm{Fe}}$, and $C_{\mathrm{H}_{2} \mathrm{O}_{2}}$ are the concentrations of $\mathrm{MO}$, catalyst and $\mathrm{H}_{2} \mathrm{O}_{2}$, respectively, $l, m$ and $n$ are order of reaction in $\mathrm{MO}$, catalyst and $\mathrm{H}_{2} \mathrm{O}_{2}$, respectively and $k$ is the rate constant. In order to calculate order of reaction in catalyst and $\mathrm{H}_{2} \mathrm{O}_{2}$, it was assumed that the apparent rate constant (calculated from pseudo first order kinetics of decolorization process, Fig. 6) is directly proportional to concentration of both catalyst and hydrogen peroxide; and hence:

$k^{*}=k C_{\mathrm{Fe}}^{m} C_{\mathrm{H}_{2} \mathrm{O}_{2}}^{n}$

$\ln k^{*}=\ln k C_{\mathrm{H}_{2} \mathrm{O}_{2}}^{n}+m \ln C_{\mathrm{Fe}}$

$\ln k^{*}=k^{* *}+m \ln C_{\mathrm{Fe}}, \quad k^{* *}=\ln k C_{\mathrm{H}_{2} \mathrm{O}_{2}}^{n}$ 
Fig. 7 Reaction kinetics of MO degradation using different initial dye Concentration: a zero-order, b half-order, c first-order, $\mathbf{d}$ second-order reaction kinetics
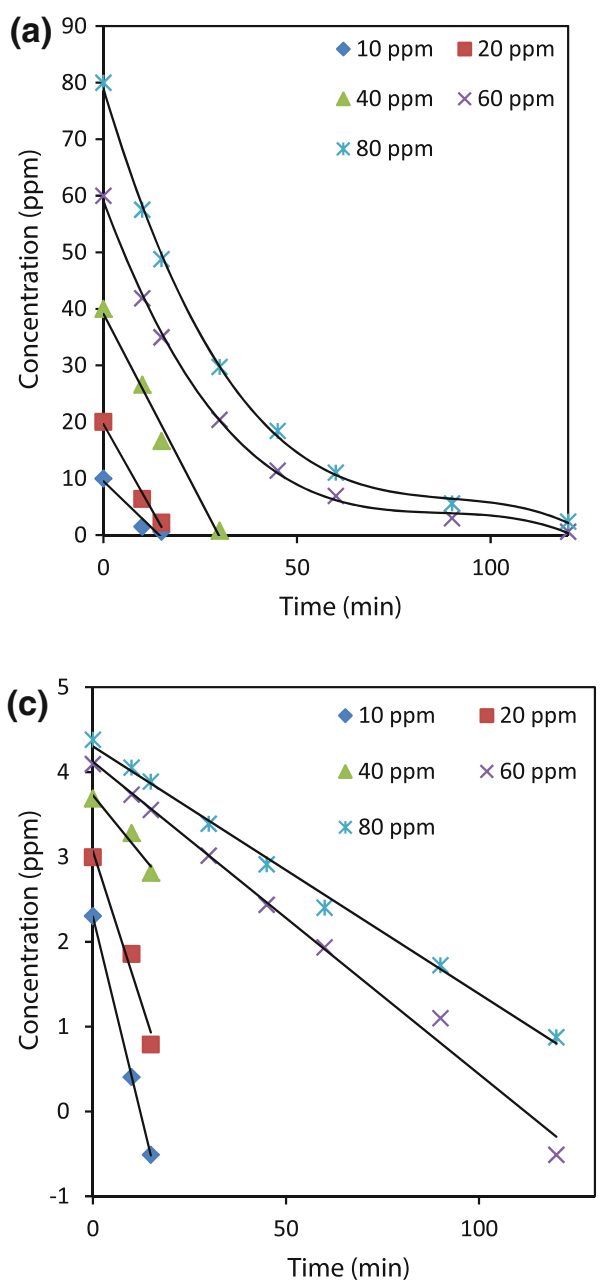
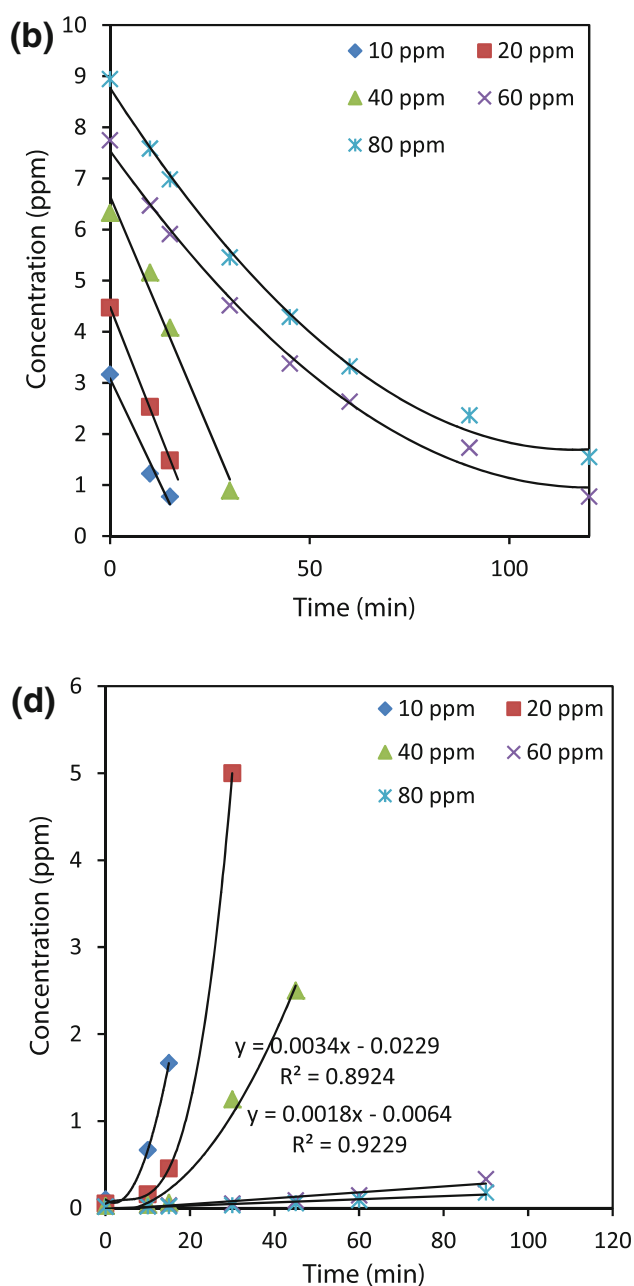

Table 1 Rate constants obtained from linear regression analysis of dye removal using different kinetic models

\begin{tabular}{|c|c|c|c|c|c|c|c|c|c|c|c|c|}
\hline \multirow{2}{*}{$\begin{array}{l}C_{0} \\
(\mathrm{ppm})\end{array}$} & \multicolumn{3}{|c|}{ Zero-oder kinetics } & \multicolumn{3}{|c|}{ Half-oder kinetics } & \multicolumn{3}{|c|}{ First-oder kinetics } & \multicolumn{3}{|c|}{ Second-oder kinetics } \\
\hline & $\begin{array}{l}k_{0} \\
\left(\mathrm{ppm} \min ^{-1}\right)\end{array}$ & $\begin{array}{l}t_{1 / 2} \\
(\min )\end{array}$ & $R^{2}$ & $\begin{array}{l}k_{0.5} \\
\left(\mathrm{ppm}^{0.5} \min ^{-1}\right)\end{array}$ & $\begin{array}{l}t_{1 / 2} \\
(\min )\end{array}$ & $R^{2}$ & $\begin{array}{l}k \\
\left(\min ^{-1}\right)\end{array}$ & $\begin{array}{l}t_{1 / 2} \\
(\mathrm{~min})\end{array}$ & $R^{2}$ & $\begin{array}{l}k_{2} \\
\left(\mathrm{ppm}^{-1} \min ^{-1}\right)\end{array}$ & $\begin{array}{l}t_{1 / 2} \\
(\mathrm{~min})\end{array}$ & $R^{2}$ \\
\hline 10 & 0.658 & 7.60 & 0.94 & 0.164 & 11.38 & 0.976 & 0.187 & 3.71 & 0.999 & - & - & - \\
\hline 20 & 1.211 & 8.26 & 0.988 & 0.198 & 13.33 & 0.999 & 0.142 & 4.88 & 0.97 & - & - & - \\
\hline 40 & 1.314 & 15.22 & 0.987 & 0.184 & 20.28 & 0.98 & 0.055 & 12.60 & 0.947 & - & - & - \\
\hline 60 & - & - & - & - & - & - & 0.036 & 19.25 & 0.992 & 0.003 & 5.56 & 0.892 \\
\hline 80 & - & - & - & - & - & - & 0.029 & 23.90 & 0.995 & 0.001 & 12.50 & 0.922 \\
\hline
\end{tabular}

where $k^{*}$ is the apparent rate constant of pseudo-first-order kinetics, $k$ is the actual rate constant.

Figure 8 represents the change in $k^{*}$ as a function in catalyst dose at $20 \mathrm{mg} / \mathrm{L}$ of dye concentration. The slope of straight lines represents order of reaction in catalyst concentration $(m)$ which was found to be 1.12 and intercept represents $k^{* *}$. The order of reaction in hydrogen peroxide concentration $(n)$ can be determined by plotting the intercepts $\left(k^{* *}\right)$ in Fig. 8 against $\ln \mathrm{H}_{2} \mathrm{O}_{2}$ concentration (Fig. 9). The calculated reaction orders in $\mathrm{H}_{2} \mathrm{O}_{2}$ concentration was
0.426. Finally, it can be concluded that the rate equation that describe decolorization of MO dye using steel industry waste is:

$$
-\frac{\mathrm{d} C_{\mathrm{MO}}}{\mathrm{d} t}=k C_{\mathrm{MO}} C_{\mathrm{Fe}}^{1.12} C_{\mathrm{H}_{2} \mathrm{O}_{2}}^{0.426}
$$

Stability and reusability of iron-containing waste

To assess the stability of iron-containing waste as catalyst in heterogeneous Fenton reaction, samples were analyzed 


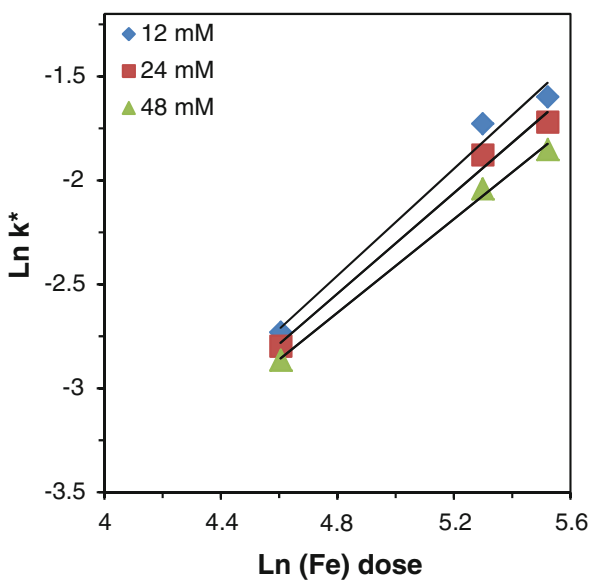

Fig. 8 Change in rate constant with catalyst concentration at different $\mathrm{H}_{2} \mathrm{O}_{2}$ concentrations; Reaction conditions: $\mathrm{pH} 2$ and $20 \mathrm{mg} / \mathrm{L} \mathrm{MO}$

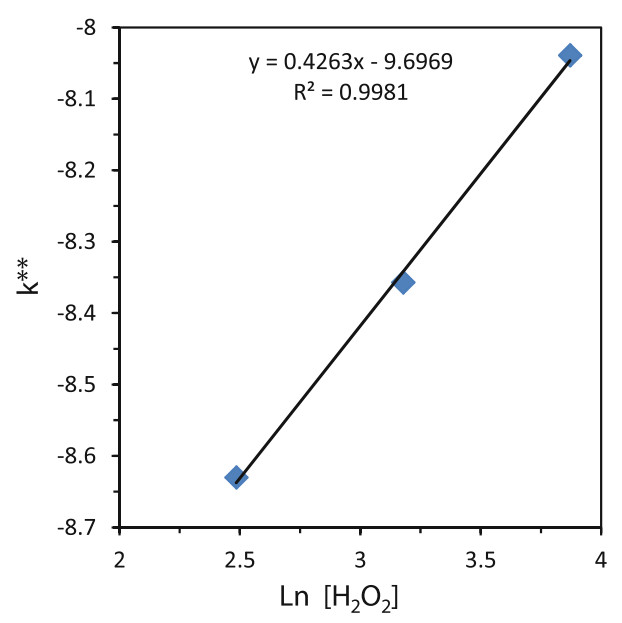

Fig. 9 Change in $k^{* *}$ with different $\mathrm{H}_{2} \mathrm{O}_{2}$ concentration

to determine the concentration of dissolved iron ions. The amount of leached iron from waste was $0.15 \mathrm{mg} / \mathrm{L}$ after $120 \mathrm{~min}$ at $\mathrm{pH} 2$. This result supports that heterogeneous Fenton reaction using steel industry waste was carried out efficiently without iron leaching and this also may support the reuse of this catalyst for several times with same efficiency. After MO decolorization, used waste (catalyst) was separated from solution by magnetic separation and reused for several consecutive MO decolorization processes. As illustrated in Fig. 10, the activity decreased gradually during successive runs. However, the removal rate was rather comparable for all the runs at longer reaction times. $96 \%$ decolorization of MO was still achieved within 45 min and after catalyst being used for 5 cycles.

\section{Conclusions}

In this study, iron-containing waste was used as a heterogeneous Fenton-catalyst. The iron-containing waste had a

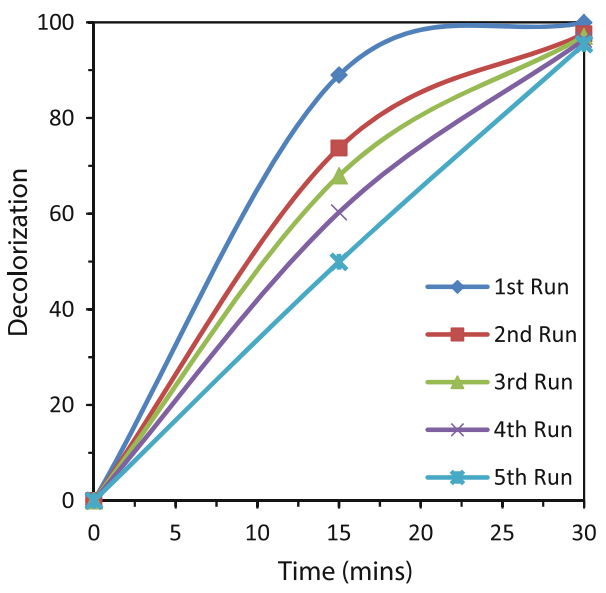

Fig. 10 Reusability and stability of catalyst

high catalytic activity toward the degradation of MO dye in the presence of $\mathrm{H}_{2} \mathrm{O}_{2}$ and in acidic $\mathrm{pH}$ range. $200 \mathrm{mg} / \mathrm{L}$ of waste could catalyze $24 \mathrm{mM} \mathrm{H}_{2} \mathrm{O}_{2}$ to achieve $99 \%$ of decolorization efficiency of solution containing $20 \mathrm{mg} / \mathrm{L}$ of MO dye in just $30 \mathrm{~min}$ at $\mathrm{pH} 2$. Different kinetic models were investigated to determine the exact rate equation that fits the experimental data. First-order kinetics was found to be the best rate equation. Order of reaction in hydrogen peroxide concentration was 0.426 , while order of reaction in catalyst concentration was 1.12 , respectively. This indicates that rate or reaction was more dependent on catalyst concentration rather than hydrogen peroxide concentration. Results also showed that the catalyst have a good stability and reusability. This study may provide useful information for the use of low cost materials as catalysts in heterogeneous Fenton process catalysts for degradation of organic pollutants.

Open Access This article is distributed under the terms of the Creative Commons Attribution License which permits any use, distribution, and reproduction in any medium, provided the original author(s) and the source are credited.

\section{References}

Bautista P, Mohedano AF, Casas JA, Zazo JA, Rodriguez JJ (2008) An overview of the application of Fenton oxidation to industrial wastewaters treatment. J Chem Technol Biotechnol 83:1323-1338

Cruz-González K, Torres-López O, García-León A, Guzmán-Mar JL, Reyes LH, Hernández-Ramírez A, Peralta-Hernández JM (2010) Determination of optimum operating parameters for Acid Yellow 36 decolorization by electro-Fenton process using BDD cathode. Chem Eng J 160:199-206

Dukkanc M, Gunduz G, Yýlmaz S, Prihodko RV (2010) Heterogeneous Fenton-like degradation of Rhodamine $6 \mathrm{G}$ in water using CuFeZSM-5 zeolite catalyst prepared by hydrothermal synthesis. J Hazard Mater 181:343-350

Feng JY, Hu XJ, Yue PL (2004) Discoloration and mineralization of Orange II using different heterogeneous catalysts containing Fe: a comparative study. Environ Sci Technol 38:5773-5778 
Garrido-Ramirez EG, Theng BKG, Mora ML (2010) Clays and oxide minerals as catalysts and nanocatalysts in Fenton-like reactions-a review. Appl Clay Sci 47:182-192

Guo LQ, Chen F, Fan XQ, Cai WD, Zhang JL (2010) S-doped Fe2O3 as a highly active heterogeneous Fenton-like catalyst towards the degradation of Acid Orange 7 and phenol. Appl Catal B Environ 96:162-168

Hassan H, Hameed BH (2011) Oxidative decolorization of Acid Red 1 solutions by $\mathrm{Fe}-$ zeolite $\mathrm{Y}$ type catalyst. Desalin 276:45-52

Ji F, Li C, Zhang J, Deng L (2011) Efficient decolorization of dye pollutants with $\mathrm{LiFe}$ (WO4)2 as a reusable heterogeneous Fenton-like catalyst. Desalin 269:284-290

Lam SW, Chiang K, Lim TM, Amal R, Low GKC (2005) The role of ferric ion in the photochemical and photocatalytic oxidation of resorcinol. J Catal 234:292-299

Li YM, Lu YQ, Zhu XL (2006) Photo-Fenton discoloration of the azo dye X-3B over pillared bentonites containing iron. J Hazard Mater B132:196-201

Li HL, Lei HY, Yu Q, Li Z, Feng X, Yang BJ (2010) Effect of low frequency ultrasonic irradiation on the sonoelectro-Fenton degradation of cationic red X-GRL. Chem Eng J 160:417-422

Liao Q, Sun J, Gao L (2009) Degradation of phenol by heterogeneous Fenton reaction using multi-walled carbon nanotube supported
Fe2O3 catalysts. Colloids Surf A Physicochem Eng Asp 345:95-100

Muthukumari B, Selvam K, Muthuvel I, Swaminathan M (2009) Photoassisted hetero-Fenton mineralization of azo dyes by Fe(II) $-\mathrm{Al}_{2} \mathrm{O}_{3}$ catalyst. Chem Eng J 153:9-15

Ramirez JH, Maldonado-Hodar FJ, Perez-Cadenas AF, MorenoCastilla C, Costa CA, Madeira LM (2007) Azo-dye Orange II degradation by heterogeneous Fenton like reaction using carbonFe catalysts. Appl Catal B Environ 75:312-323

Romero A, Santos A, Vicente F (2009) Chemical oxidation of 2,4dimethylphenol in soil by heterogeneous Fenton process. J Hazard Mater 162:785-790

Xu L, Wang J (2011) A heterogeneous Fenton-like system with nanoparticulate zero-valent iron for removal of 4-chloro-3methyl phenol. J Hazard Mater 186:256-264

Zhang JB, Zhuang J, Gao LZ, Zhang Y, Hu N, Feng J, Yang DL, Zhu JD, Yan XY (2008) Decomposing phenol by the hidden talent of ferromagnetic nanoparticles. Chemosphere 73:1524-1528

Zhang H, Fu H, Zhang DB (2009) Degradation of C.I. Acid Orange 7 by ultrasound enhanced heterogeneous Fenton-like process. J Hazard Mater 172:654-660 